\title{
Silica Based Superhydrophobic Nanocoatings for Natural Rubber Surfaces
}

\author{
Veromee Kalpana Wimalasiri, ${ }^{1}$ Helapiyumi Uthpala Weerathunga, ${ }^{1}$ \\ Nilwala Kottegoda, ${ }^{1,2,3}$ and Veranja Karunaratne ${ }^{1,4}$ \\ ${ }^{1}$ Sri Lanka Institute of Nanotechnology, Nanotechnology \& Science Park, Mahenwatte, Pitipana, Homagama, Sri Lanka \\ ${ }^{2}$ Department of Chemistry, University of Sri Jayewardenepura, Sri Soratha Mawatha, 10250 Nugegoda, Sri Lanka \\ ${ }^{3}$ Center for Advanced Materials Research, Faculty of Applied Sciences, University of Sri Jayewardenepura, Nugegoda, Sri Lanka \\ ${ }^{4}$ Department of Chemistry, University of Peradeniya, Galaha Rd, 20400 Peradeniya, Sri Lanka
}

Correspondence should be addressed to Nilwala Kottegoda; nilwalak@slintec.lk

Veromee Kalpana Wimalasiri and Helapiyumi Uthpala Weerathunga contributed equally to this work.

Received 30 March 2017; Revised 1 June 2017; Accepted 19 June 2017; Published 8 August 2017

Academic Editor: Silvia Licoccia

Copyright (C) 2017 Veromee Kalpana Wimalasiri et al. This is an open access article distributed under the Creative Commons Attribution License, which permits unrestricted use, distribution, and reproduction in any medium, provided the original work is properly cited.

\begin{abstract}
Silica based nonfluorinated superhydrophobic coatings for natural rubber surfaces have been developed. The coating was synthesized using nanosilica dispersion and a polychloroprene type binder as a compatibilizer. This nanocoating of silica was applied on to the surface of finished natural rubber gloves, by spray coating or dipped coating methods. The nanocoating demonstrates a water contact angle of more than $150^{\circ}$ and sliding angle of $7^{\circ}$. The morphological features of the coating have been studied using scanning electron microscopy and atomic force microscopy while Fourier transform infrared spectroscopy was used to understand the nature of surface functional groups. Both imaging techniques provided evidence for the presence of nanosized particles in the coating. Coated gloves demonstrated comparable mechanical properties and significantly better alcohol resistivity when compared to those of the uncoated gloves.
\end{abstract}

\section{Introduction}

Nanotechnology has recently gained the industrial attention as a sustainable way to solve many of the problems associated with the current society. It has been effectively implemented in many fields such as agriculture, water purification, energy, and medical and polymer industry [1]. Amongst these applications many functional nanomaterials have been utilized in polymer industry in order to impart various properties to the products.

The concept of superhydrophobicity has been widely exploited during the past decade due to the potential applications in impermeable textiles, self-cleaning coatings, labon-a-chip devices, microfluidic devices, and glasses [2-7]. A surface is defined as superhydrophobic when its contact angle is more than $150^{\circ}$ and the sliding angle is less than $10^{\circ}$ [8]. This phenomenon is naturally observed in numerous biological surfaces such as the lotus leaf, the namib, the desert beetle, and the water strider [9-11]. Thus, many methods in creating superhydrophobicity on different material surfaces have been achieved through the biomimetic approach $[12,13]$.

$\mathrm{Yu}$ et al. have synthesized hydrophobic silica aerogel spheres by a coprecursor method. Here, a contact angle of $152^{\circ}$ was achieved [14]. Seyedmehdi et al. have also synthesized superhydrophobic room temperature vulcanized silicone rubber insulator coatings with a contact angle of $145^{\circ}$ and good UV durability [15]. Meanwhile, nanoscale surface roughness has been achieved by Mates et al. using paraffin wax-polyolefin thermoplastic blend (elastomer matrix binder) with bulk-produced carbon nanofibers as a stretchable coating for low-cost ultraflexible electronics [16]. Moreover, superhydrophobicity has been obtained by Bayer et al. using different types of rubber reinforced biopolymer/ organoclay nanocomposite coatings. Here, a biolubricant has 
been used to cause hydrophobic phase inversion. Synthetic and fluoroacrylic rubber containing nanocomposite have shown better self-cleaning properties than natural rubber reinforced nanocomposite [17].

Silicone rubber and nanofluoric particles have been mixed in order to obtain superhydrophobic characteristics on silicon rubber surfaces by Seyedmehdi et al. [18]. Kato et al. have reported the synthesis of silica-filled crosslinked natural rubber which exhibit both hydrophobic and hydrophilic properties [19]. Simpson et al. have reviewed historic limitations of superhydrophobic surfaces and coatings, supplementing recent superhydrophobic breakthroughs such as resin marbles, volumetric superhydrophobic coatings, and water marbles which can be used for a wide range of applications [20]. Moreover, superhydrophobic aluminum surfaces have been fabricated using a simple spray coating approach where the coating consists of wear abrasion resistant acrylonitrile butadiene styrene rubber and hydrophobic silica nanoparticles. This superhydrophobic coating has shown extreme thermal properties which does not degrade until $420^{\circ} \mathrm{C}$ [21]. Historically, fluorinated hydrocarbon based coatings have been utilized in superhydrophobic applications. Silica sol-gel based coatings fabricated using longchain fluoroalkylsilane was reported by Liu et al. recently, exhibiting a water contact angle of $169^{\circ}$ [22]. However, these compounds are currently identified as carcinogenic where Wang et al. have reported polyfluorinated iodine alkanes can act on estrogen receptors subsequently, causing detrimental effects on reproductive and development systems [23]. Therefore, there is an increased interest in developing alternative coatings [24]. In this context, silica aerogels and silica based nanomaterials have been identified as potential materials.

Silica aerogels are translucent and thermal insulating materials consisting of nanosized pores, networked together to form an open, highly porous structure. As a result, they possess a large surface area $\left(500-1500 \mathrm{~m}^{2} / \mathrm{g}\right)$, high porosity (80-99\%), and low bulk density $\left(0.03-0.35 \mathrm{~g} / \mathrm{cm}^{3}\right)$. In addition, they demonstrate small pore sizes ranging between 1 and $100 \mathrm{~nm}$. Low index of refraction ( 1.05) and high optical transmission ( $\sim 93 \%)$ impart transparent characteristics into silica aerogel materials [25-29]. In superhydrophobic applications, silica aerogel is generally modified with a suitable long-chain alkyl groups.

This study focuses on the development of a novel superhydrophobic nanocoating on natural rubber surfaces. An organically modified silica aerogel based coating formulation was developed where an added polychloroprene based polymer compatibalizes the coating onto the rubber surface. The structural features, mechanical properties, and chemical resistivity have been studied and compared with those of uncoated natural rubber gloves.

\section{Experimental Methods and Materials}

2.1. Materials. L-Turpentine (99\%), ethyl acetate ( $\geq 99.5 \%)$, methanol (80\%), and formic acid (>99\%) were purchased from Sigma-Aldrich. Enova IC3100 silica aerogel (particle size $2-40 \mu \mathrm{m}$ ) was purchased from Cabot Cooperation.
Deuterium oxide $(99.9 \%$ atom D) was purchased from Sigma-Aldrich. Silicone sealant (BS 200 GP) was purchased from Bossil. Polymeric binder (refer to supplementary data, in Supplementary Material available online at https://doi.org/10.1155/2017/2102467) (86\%) was purchased from Sinwa Holdings, Sri Lanka. The molecules of all the ingredient materials are shown in Figure 1. Finished natural rubber gloves were purchased from a commercial supplier in Sri Lanka.

\subsection{Experimental Procedure}

2.2.1. Preparation of Silica Based Nanocoatings. The superhydrophobic coating solution was prepared by mixing $250 \mathrm{~g}$ of silicone sealant and $40 \mathrm{~g}$ of organically modified silica aerogel with $2 \mathrm{dm}^{3}$ of turpentine. The mixture was stirred for one hour at $500 \mathrm{rpm}$ and, then, it was sonicated for 10 minutes in an ultrasonic bath. The viscosity of the silica coating was optimized at a value of 1.2 Pa.s. The nanocoating was applied onto the natural rubber glove surface by dipped coating and spray coating methods.

2.2.2. Preparation of Compatibilizer Solution. The nanocoating and the rubber surface were compatibilized using an appropriate binder. The binder solution was prepared by mixing polychloroprene binder $(500 \mathrm{~g})$ with ethyl acetate $(500 \mathrm{~g})$ at a mixing ratio of $1: 1(\mathrm{w} / \mathrm{w})$. The resulting mixture was stirred for one hour at $500 \mathrm{rpm}$ at room temperature followed by ultrasound sonication for 10 minutes in an ultrasonic bath. After several trials the viscosity of the binder solution was optimized at a value of $1.4 \mathrm{~Pa} \cdot \mathrm{s}$.

\subsubsection{Application of Silica Nanocoating on to Natural Rubber} Gloves: Dipped Coating Method. Vulcanized natural rubber gloves were dressed onto a ceramic former and dipped in the binder solution for $10 \mathrm{~s}$ after which the former was withdrawn. Then, the former was rotated in all 3 directions for about $40 \mathrm{~s}$. The glove coated with the binder solution was then immersed ( $30 \mathrm{~cm}$ dipped length) in the silica dispersion for $10 \mathrm{~s}$. The gloves were withdrawn from the silica dispersion in a slow manner (15 s withdrawal time per $30 \mathrm{~cm}$ length). The procedure was repeated to obtain two coatings and, then, the gloves were cured in an oven at $50^{\circ} \mathrm{C}$ for $24 \mathrm{~h}$. The same procedure was repeated to coat a rubber film where the nanocoating did not contain silica aerogel. Figure 2 shows the appearance of a water drop upon contact with the coated and uncoated films.

\subsubsection{Application of Silica Based Nanocoating onto Natural} Rubber Gloves: Spray Coating Method. Natural rubber gloves were dressed onto a ceramic former and dipped in the binder solution for $10 \mathrm{~s}$ after which the former was withdrawn. Then, the former was rotated in all 3 directions for about $40 \mathrm{~s}$. Subsequently, the silica dispersion was spray coated (H2000 mini HVLP traditional autospray gun with $0.8 \mathrm{~mm}$ nozzle supplied with $2 \mathrm{MPa}$ compressed air). The distance between the nozzle of the gun and rubber surface was maintained at $10 \mathrm{~cm}$. Silica dispersion $(10 \mathrm{ml})$ was coated onto the glove 
<smiles>CCc1cc(C)c(O)c(Cc2cc(C)c(O)c(Cc3cc(C)c(O)c(Cc4cc(Cc5cc(Cc6cc(C)c(O)c(C)c6)cc(C(C)C)c5O)cc(C)c4O)c3)c2)c1</smiles>

Phenol formaldehyde resin<smiles>CC(=O)O[Si](C)(OC(C)=O)OC(C)=O</smiles>

MTAS<smiles>CCC=C(Cl)CC</smiles>

Polychloroprene<smiles>CCC(=O)O[Si](CC)(OC(C)=O)OC(=O)CC</smiles>

ETAS

FIGURE 1: Molecules of ingredient materials of the nanocoating (methyltriacetoxysilane (MTAS) and ethyltriacetoxysilane (ETAS)) and the binder (phenol formaldehyde resin and polychloroprene).

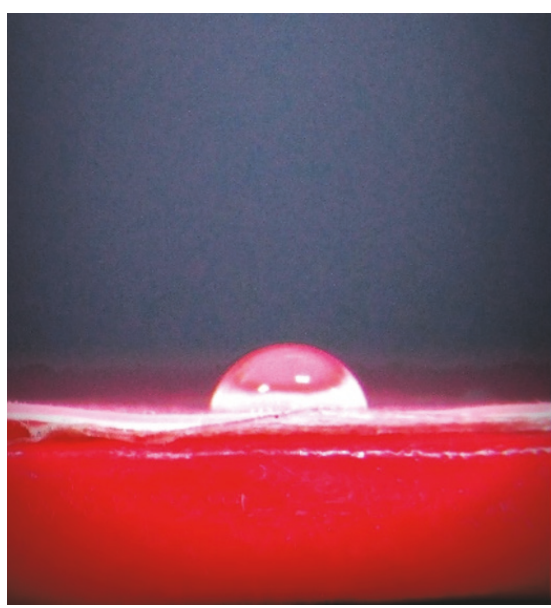

(a)

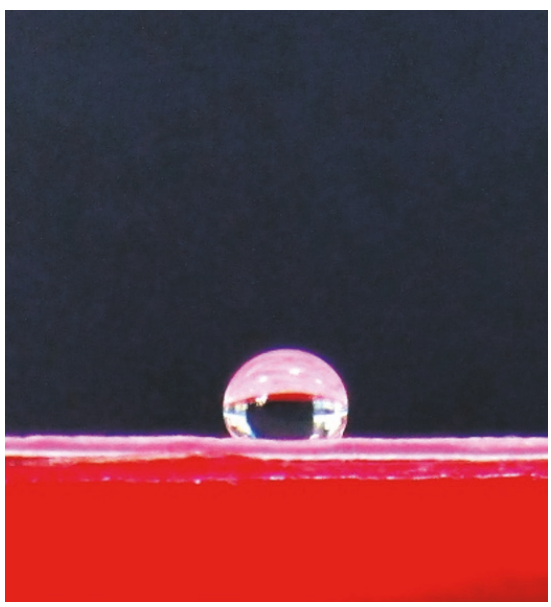

(b)

Figure 2: Water droplet on (a) uncoated rubber surface and (b) silica nanocoated rubber surface.

surface. The former was rotated in all 3 directions for $1 \mathrm{~min}$. This procedure was repeated to obtain two coatings. Then, the former was cured at $50^{\circ} \mathrm{C}$ for $24 \mathrm{~h}$ in an oven. The same procedure was repeated to coat a rubber film where the nanocoating did not contain silica aerogel. However this film did not show any superhydrophobic property.

\subsection{Characterization}

2.3.1. Stress-Strain Properties of the Coated Glove Samples. Both spray coated and dipped coated natural rubber gloves were tested for their stress and strain properties using Instron 55R1123 tensile testing machine. The coated rubber glove samples were molded into a dumbbell shaped test specimen (ASTM D412) using a mold. The length, width, and thickness of the samples were $70 \mathrm{~mm}, 10 \mathrm{~mm}$, and $2.15 \mathrm{~mm}$, respectively. The machine was equipped with a $1 \mathrm{kN}$ load cell and operated at a crosshead speed of $500 \mathrm{~mm} / \mathrm{min}$.

2.3.2. Fourier Transform Infrared (FT-IR) Spectroscopy. The FT-IR spectrum of natural rubber, polychloroprene binder, and dipped coated and spray coated natural rubber materials were obtained using the diffuse reflectance mode over the range of $600-3500 \mathrm{~cm}^{-1}$ using Bruker Vertex 80 at a resolution of $4 \mathrm{~cm}^{-1}$. 


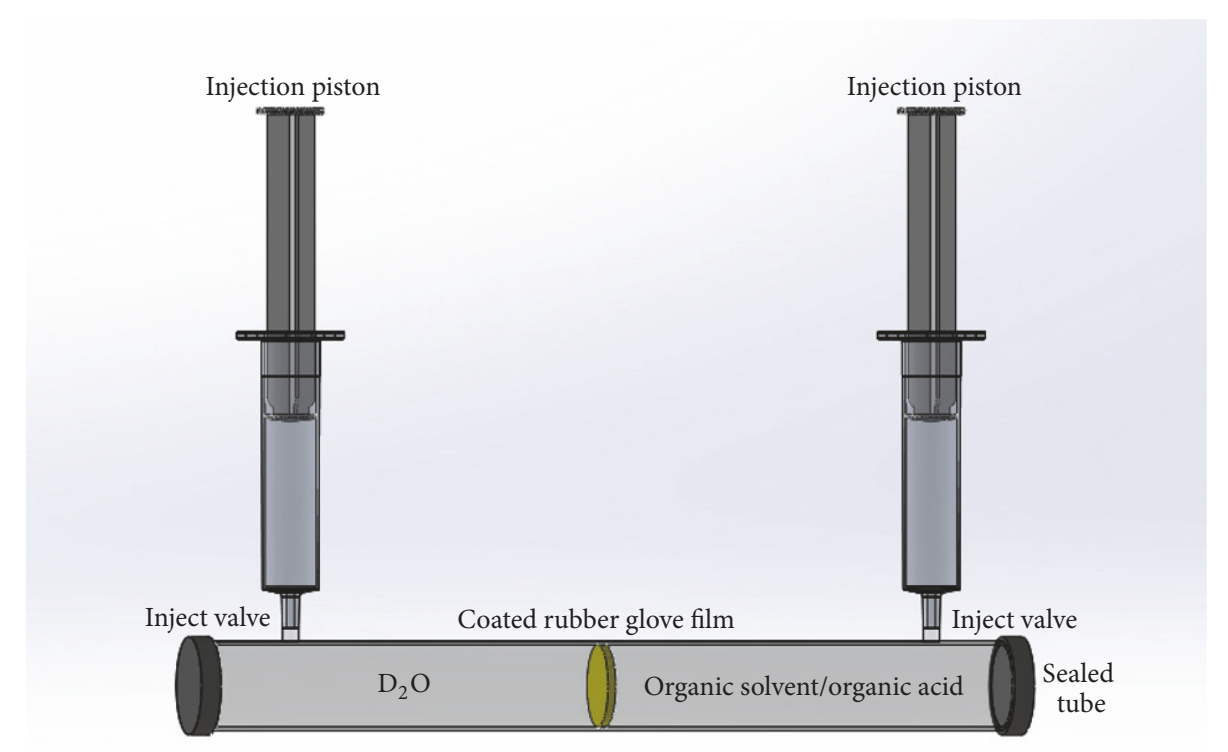

FIGURE 3: The apparatus for measurement of organic solvent permeation through the rubber film.

2.3.3. Scanning Electron Microscope (SEM) Spectroscopy. Surface morphology characteristics of the superhydrophobic natural rubber materials were analyzed using a SU 6600 HITACHI scanning electron microscope (SEM) under the operating voltage of $5.0-10.0 \mathrm{kV}$. The glove samples were mounted onto an aluminum stub and a thin coating of gold was applied. The surface was imaged in the secondary electron mode. Quantitative analysis of the nanocoating was carried out using energy dispersing X-ray (EDX) analysis.

A drop of the liquid superhydrophobic nanocoating was kept over an aluminum SEM stub and was kept in the oven for 24 hours at $60^{\circ} \mathrm{C}$ for drying. After the drying process, a thin gold coating was applied. EDX analysis was replicated three times from three different places of the same specimen. The average values of the three readings were recorded.

2.3.4. Atomic Force Microscope (AFM) Spectroscopy. Threedimensional surface features of the coated rubber material were observed and analyzed using a Park System AFM XE-100 microscope, under air at room temperature with a scanning rate of $0.5 \mathrm{~Hz}$ in noncontact mode with a $1650-00$ type silicone tip.

2.3.5. Water Contact Angle (WCA) and Sliding Angle (SA) Measurements. A goniometer was used to measure the water contact angle of coated and uncoated rubber films. A high resolution digital camera (Cannon, macro mode) was used to capture the images which were set to the goniometer apparatus. Water droplet size used to measure contact angle was $\sim 5 \mu \mathrm{L}$, and the droplet diameter was $\sim 1 \mathrm{~mm}$ when it settled on the rubber surface. Five replicates were used to calculate an average contact angle value for each sample.
The same experiment was carried out for low molecular weight organic solvents and coconut oil to study the oleophobicity of the surface.

The sliding angle was measured with a sliding angle measurement system where the water droplet volume used for the measurement was $5 \mu \mathrm{L}$. Water droplet was kept on flat surface of the system. The sliding angles (the critical angle where a water droplet with a certain weight begins to slide down the inclined plate) were measured. Ten replicates were used to calculate an average sliding angle value for each sample.

2.3.6. Durability of the Nanocoating. An abrasion force was applied on the film using a disc shaped rough surface $(25 \mathrm{kN})$. After each abrasion cycle contact angle of the surface was measured.

2.3.7. Permeability of Organic Solvents and Organic Acids. A special apparatus was designed (Figure 3) to study the permeability characteristics of the coated gloves towards organic solvents and dilute organic acids. A horizontal flow of the solvent and acid was maintained via the rubber film. The coated side of the rubber glove film was exposed to formic acid $\left(6 \mathrm{~cm}^{3}, 0.8 \mathrm{~mol} \mathrm{dm}{ }^{-3}\right)$. The uncoated side of the rubber film was exposed to deuterium oxide $\left(10 \mathrm{~cm}^{3}\right.$ of $\left.\mathrm{D}_{2} \mathrm{O}\right)$ as shown in Figure 3. The procedure was repeated for methanol $\left(6 \mathrm{~cm}^{3}, 0.8 \mathrm{~mol} \mathrm{dm}^{-3}\right)$ in order to understand the permeation properties of the film towards low molecular weight organic solvents. A Bruker Ascend TM 400 NMR spectrometer was used to detect the presence of formic acid/methanol in $\mathrm{D}_{2} \mathrm{O}$. The time taken for solvent/acid to penetrate through the film was measured. The same procedure was repeated for the 
TABLE 1: Mechanical properties of the coated natural rubber surfaces.

\begin{tabular}{lccr}
\hline Property & Control & $\begin{array}{c}\text { Sample } \\
\text { Dipped coated }\end{array}$ & Spray coated \\
\hline Cure time (hours) & 24 & 24 & 24 \\
Cure temperature $\left({ }^{\circ} \mathrm{C}\right)$ & 50 & 50 & 50 \\
Tensile strength $(\mathrm{MPa})$ & $16.22 \pm 6.09$ & $11.58 \pm 2.24$ & $15.65 \pm 1.35$ \\
Mod $100 \%(\mathrm{MPa})$ & $1.40 \pm 0.13$ & $1.36 \pm 0.08$ & $1.44 \pm 0.25$ \\
Mod $500 \%(\mathrm{MPa})$ & $8.35 \pm 1.54$ & $7.43 \pm 2.44$ & $8.58 \pm 1.55$ \\
Tear strength $(\mathrm{kN} / \mathrm{m})$ & $43.48 \pm 5.66$ & $29.39 \pm 1.90$ & $30.52 \pm 2.38$ \\
\hline
\end{tabular}

uncoated gloves as well. The morphological changes after the exposure to organic solvents/acid were studied using the SEM technique.

\section{Results and Discussion}

3.1. Mechanical Properties. Tensile and tear properties of the superhydrophobic gloves prepared by the spray and the dipped coating methods were compared with those of uncoated gloves (Table 1). The properties of spray coated gloves were similar to that of uncoated gloves while significant deterioration of mechanical properties was observed when the gloves were coated by the dipping technique. Unlike with the spray coating method, during the dipped coating, the rubber matrix is exposed to organic solvents for prolonged time intervals, leading to swelling of the natural rubber matrix. Such interactions lead to a reduction of mechanical properties and chemical changes in the structure of the polymer matrix can have a direct impact on the extent of interactions between the coating and the rubber glove.

\subsection{FT-IR Characterization of Natural Rubber and Coated} Rubber. The FT-IR characterization data is summarized in Table 2 and shown in Figures 4 and 5. In the uncoated rubber film, intense peaks appearing between $3000 \mathrm{~cm}^{-1}$ and $2750 \mathrm{~cm}^{-1}$ are corresponding to $\mathrm{CH}_{2}$ symmetric stretching vibrations. In the coatings made by both spray and dipped coating methods, the above peaks appear at the same position, though with a significant reduction in their intensity. This concludes that the $\mathrm{CH}_{2}$ groups in natural rubber were unaffected by the interactions between the coating and natural rubber surface. The $\mathrm{C}=\mathrm{C}$ of uncoated rubber was observed at $1660 \mathrm{~cm}^{-1}$. In the coated gloves this peak appears at $1657 \mathrm{~cm}^{-1}$, suggesting that the nanocoating had not chemically interacted with the double bonds of 1,4polyisoprene units of the natural rubber.

The $-\mathrm{CH}_{2}$ deformation peaks appearing at $1375 \mathrm{~cm}^{-1}$ and $1445 \mathrm{~cm}^{-1}$ for natural rubber had shifted to $1446 \mathrm{~cm}^{-1}$ and $1483 \mathrm{~cm}^{-1}$, respectively, in the coated films. This significant change suggests that the free deformations of $-\mathrm{CH}_{2}$ are being affected by the presence of coating. Furthermore, $\mathrm{C}-\mathrm{H}$ in plane bending peaks observed in uncoated samples appearing at $1038 \mathrm{~cm}^{-1}$ and $1091 \mathrm{~cm}^{-1}$ had shifted to $1009 \mathrm{~cm}^{-1}$ and $1010 \mathrm{~cm}^{-1}$, respectively, after coating $[30,31]$.

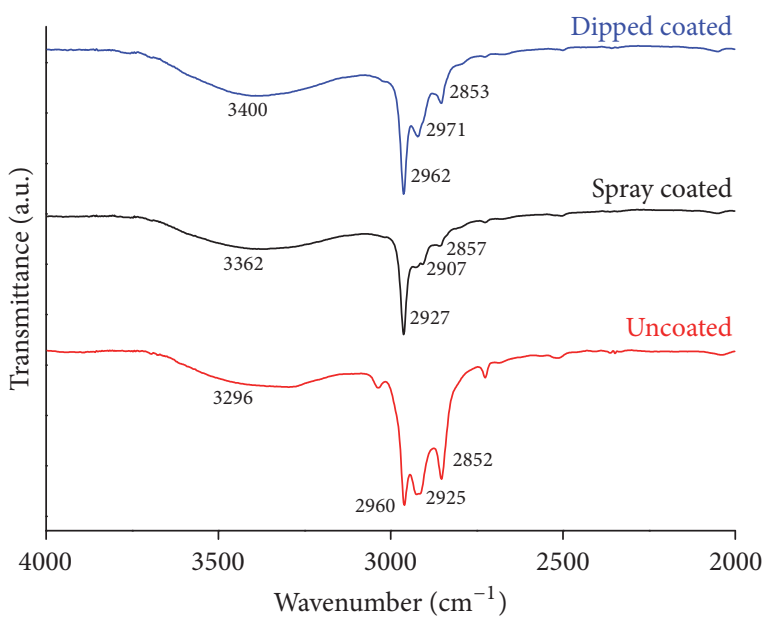

FIGURE 4: FT-IR spectrums of coated and uncoated rubber wavelength ranging from $2000 \mathrm{~cm}^{-1}$ to $4000 \mathrm{~cm}^{-1}$.

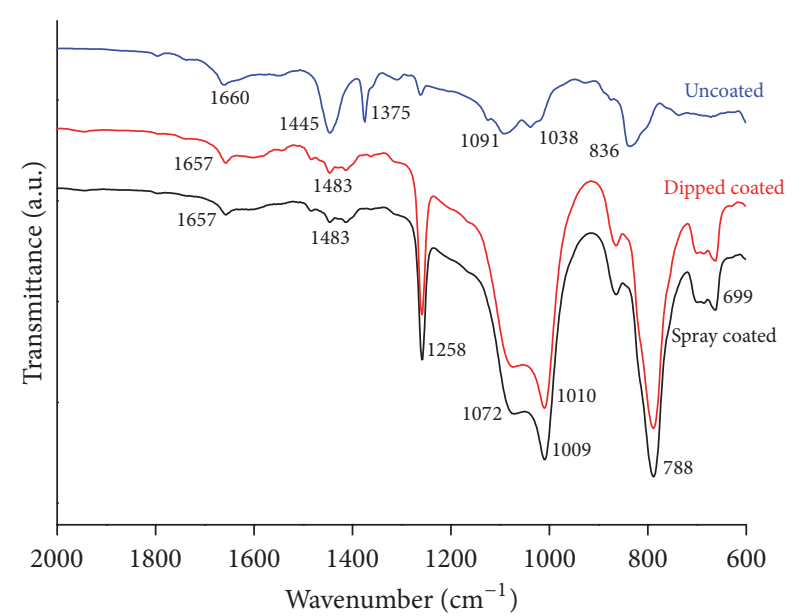

FIGURE 5: FT-IR spectrums of coated and uncoated rubber wavelength ranging from $600 \mathrm{~cm}^{-1}$ to $2000 \mathrm{~cm}^{-1}$.

In pure silica aerogel, $\mathrm{Si}-\mathrm{O}-\mathrm{Si}$ asymmetric and symmetric vibrations appear at $1018 \mathrm{~cm}^{-1}$ and $803 \mathrm{~cm}^{-1}$, respectively. After the nanocoating is applied, these two peaks have clearly shifted to $1072 \mathrm{~cm}^{-1}$ and $788 \mathrm{~cm}^{-1}$ wavenumber, respectively. 


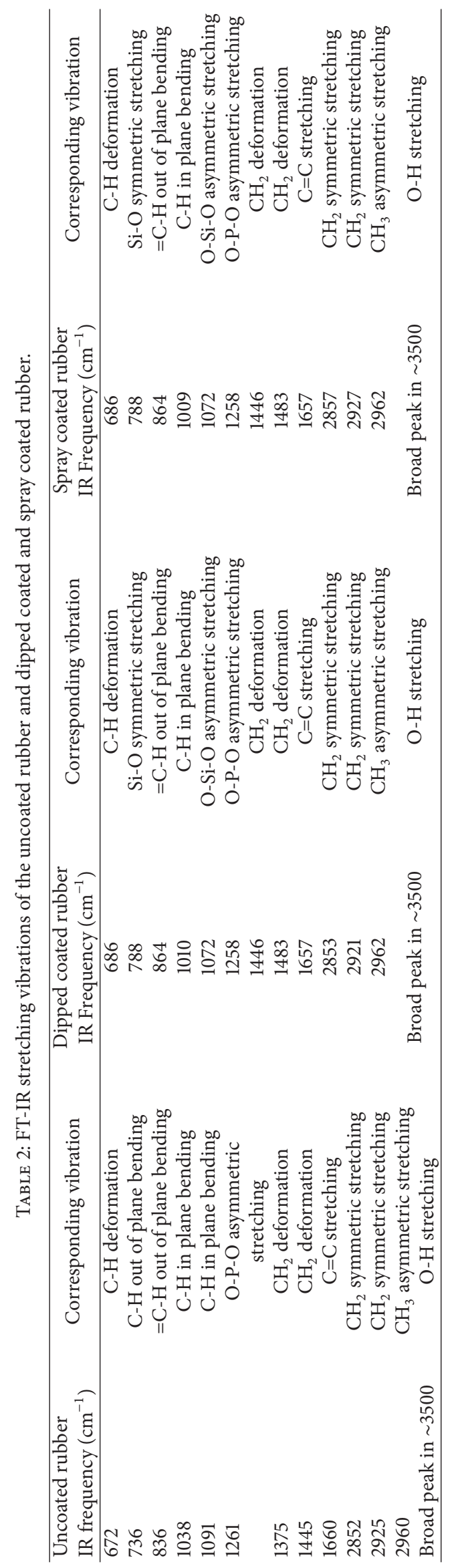




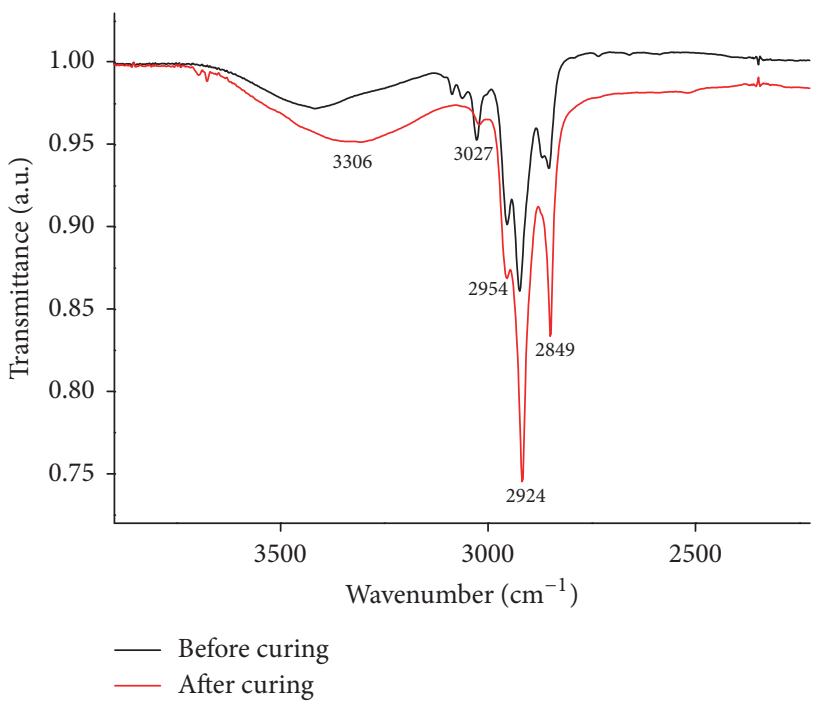

(a)

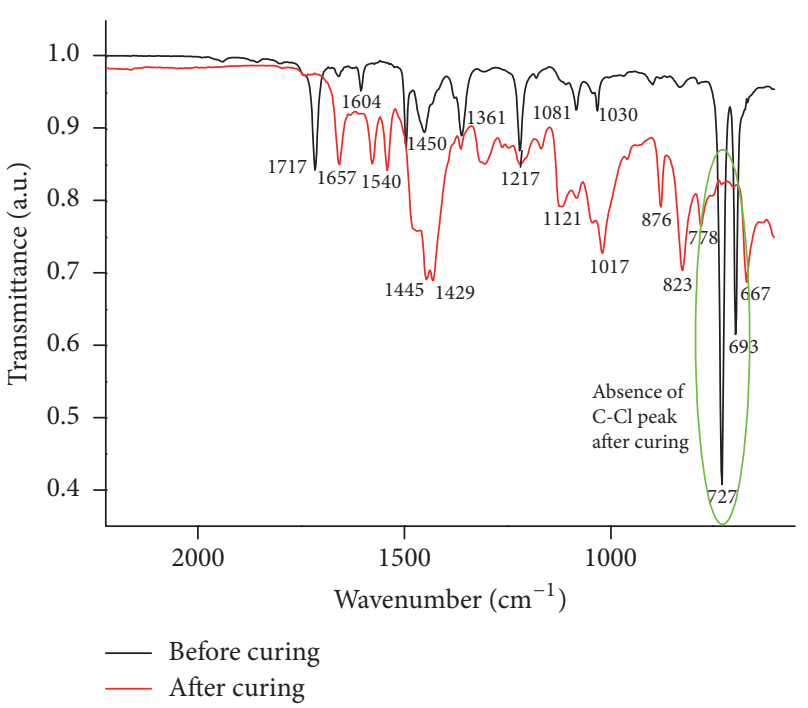

(b)

FIGURE 6: FT-IR spectrums of binder before and after curing (a) wavelength ranging from $3900 \mathrm{~cm}^{-1}$ to $2225 \mathrm{~cm}^{-1}$ and (b) wavelength ranging from $2224 \mathrm{~cm}^{-1}$ to $550 \mathrm{~cm}^{-1}$.

This suggests a clear change in electron density around $\mathrm{O}$ $\mathrm{Si}-\mathrm{O}$ bond after interacting with rubber surface [32]. Therefore, FT-IR data confirms that there are strong interactions between the coating and rubber film.

\subsection{Bonding Mechanism between the Rubber Film and the} Coating. The mechanism of the interactions between the nanocoating and the rubber film can be understood referring to the chemistry between the silica aerogel, silicone sealant, and the polychloroprene binder. Here, polychloroprene and phenol formaldehyde compatibilize the nanocoating onto the natural rubber film while silicone sealants containing methyltriacetoxysilane (MTAS) and ethyltriacetoxysilane (ETAS) act as coupling agents, binding the silica aerogel to the phenol formaldehyde unit of the binder.

Firstly, the coupling agents in silicone sealant and the silica aerogel are converted into their hydrolyzed state according to reaction mechanism shown in Figure 7 . This process is enhanced by the presence of atmospheric moisture deposited on the natural rubber surface. The two coupling agents of silicone sealant, that is, MTAS and ETAS, will replace all of its $\mathrm{Si}-\mathrm{O}-\mathrm{C}$ bonds by $\mathrm{Si}-\mathrm{OH}$ bonds.

Considering the structure of polychloroprene and phenol formaldehyde it is reasonable to argue that the $\mathrm{OH}$ groups of phenol formaldehyde interact with $\mathrm{C}$-Cl group of polychloroprene forming a chemical bond with two matrices as shown in Figure 8. This argument is supported by the FT-IR data (Table 3 ) of cured polychloroprene and phenol formaldehyde resin. As given in the FT-IR data, peak due to $\mathrm{C}-\mathrm{Cl}$ stretching frequency has disappeared after curing (Figure 6). Thus, it can be confirmed that a chemical change has occurred in $\mathrm{C}$ $\mathrm{Cl}$ bond of polychloroprene. Furthermore, $\mathrm{C}=\mathrm{C}$ stretching peak of polychloroprene has depleted after curing. It further suggests that electron density around $\mathrm{C}-\mathrm{Cl}$ has changed due to the interaction with resin.
Step 1 (hydrolysis). The hydrolysis of silica aerogel, methyltriacetoxysilane (MTAS), and ethyltriacetoxysilane (ETAS) will produce hydroxyl groups on the silicone atom. These hydrolyzed compounds will further undergo polycondensation reaction.

Step 2 (polycondensation of the silicone sealant and silica aerogel). When the coating is cured, Si-O-Si bonds of all the materials will be formed through elimination of water molecules. This elimination happens during the curing process. The hydrolyzed MTAS and ETAS will be bonded to the phenol formaldehyde unit of the binder while natural rubber interacts through polymer-polymer interaction with the polychloroprene unit of the binder.

Compatibility of natural rubber and binder is controlled by the presence of $\Pi$-bond interactions between natural rubber and polychloroprene and the $\Pi$-bond interactions between natural rubber and benzene groups of phenol formaldehyde resin. Furthermore, the flat orientation of the phenolformaldehyde ring structure provides geometrically favorable arrangement for the nanocoating to be bonded to the rubber matrix. A possible mechanism is suggested in Figure 9.

3.4. SEM Characterization of Rubber Surfaces. SEM images of natural rubber and coated rubber surfaces are given in Figure 10. Both spray coated and dipped coated natural rubber films demonstrated a rough surface with a porous microstructure. The surface of the spray coated gloves appears to be rougher than the dipped coated surface due to the presence of nanosized particles embedded within the matrix. The particle size plays a major role in imparting superhydrophobicity to the coating, reducing the interfacial area between water droplets and the surface [7]. However, 
Reaction A: hydrolysis of silica aerogel

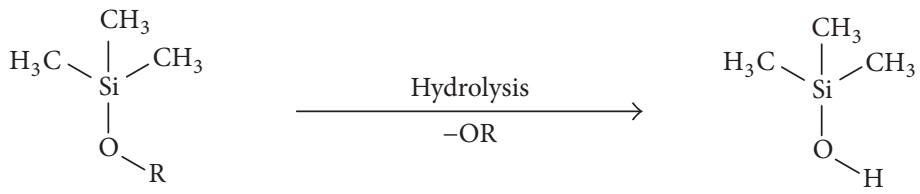

Modified silica aerogel

Hydrolyzed silica aerogel

Reaction B: hydrolysis of MTAS

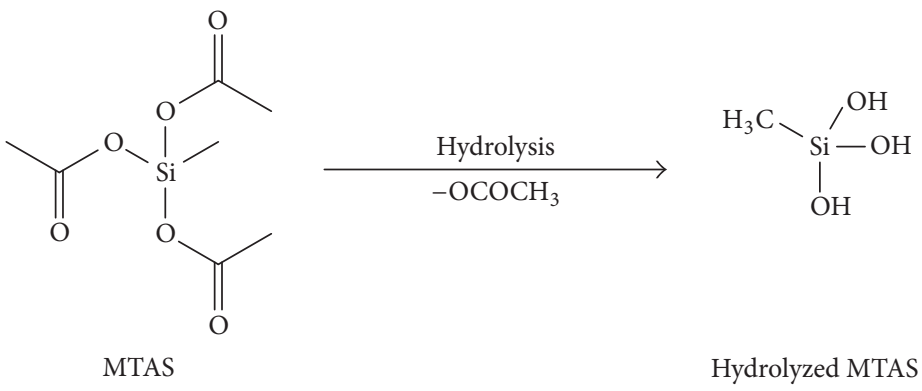

Reaction C: hydrolysis of ETAS

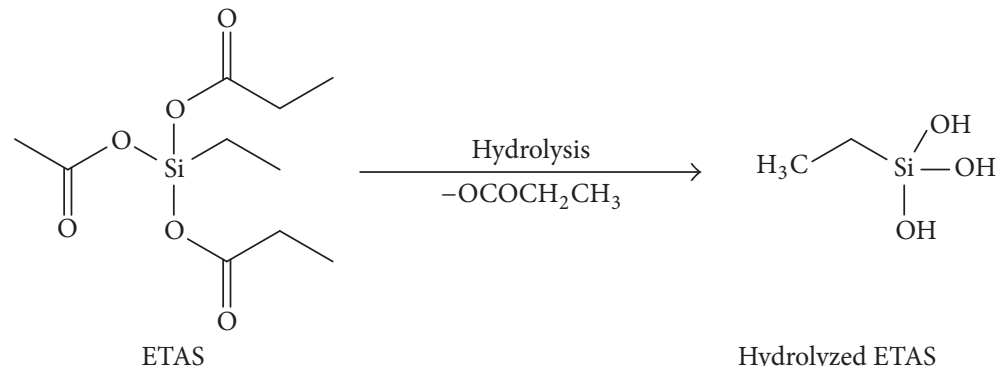

FIGURE 7: Reaction mechanisms of hydrolyzing process.

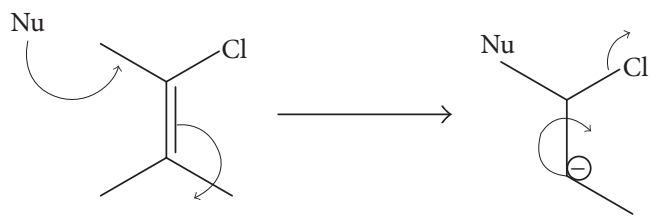

FIGURE 8: OH group of the resin attacking the polychloroprene unit and substitution of chlorine atom. OH group is denoted as Nu.

SEM images do not provide conclusive evidences regarding the best technique to obtain higher hydrophobic characteristics. Therefore, AFM characterization was carried out to understand the nanolevel morphological characteristics and surface roughness.

3.4.1. EDX Analysis of Superhydrophobic Nanocoating. EDX results confirmed the elemental composition of the nanocoating as $\mathrm{O}, \mathrm{C}$, and $\mathrm{Si}$. According to the results summarized in Table 4 it is possible to conclude that the coating does not contain any fluorinated compounds. Moreover, the presence of high \% of carbon confirms that the coating contains silica nanoparticles modified with an organic modifier.
3.5. AFM Characterization of Rubber Surfaces. As shown in Figure 11, the three-dimensional surface of the spray coated rubber surface demonstrates sphere-like shapes in its topological image. Surface roughness of the spray coating has an average thickness of $100 \mathrm{~nm}$ and a root mean square roughness of $81 \mathrm{~nm}$. A continuous coating is obtained when it is spray coated onto rubber surface where the roughness along the surface is not uniform. This increased roughness at nanoscale facilitates superhydrophobicity on the surface coating. According to Figure 12(b) the topology of dipped coating surface has a similar sphere shape appearance. The dipped coated rubber surface, however, does not have a continuous coating compared to spray coated gloves. In 


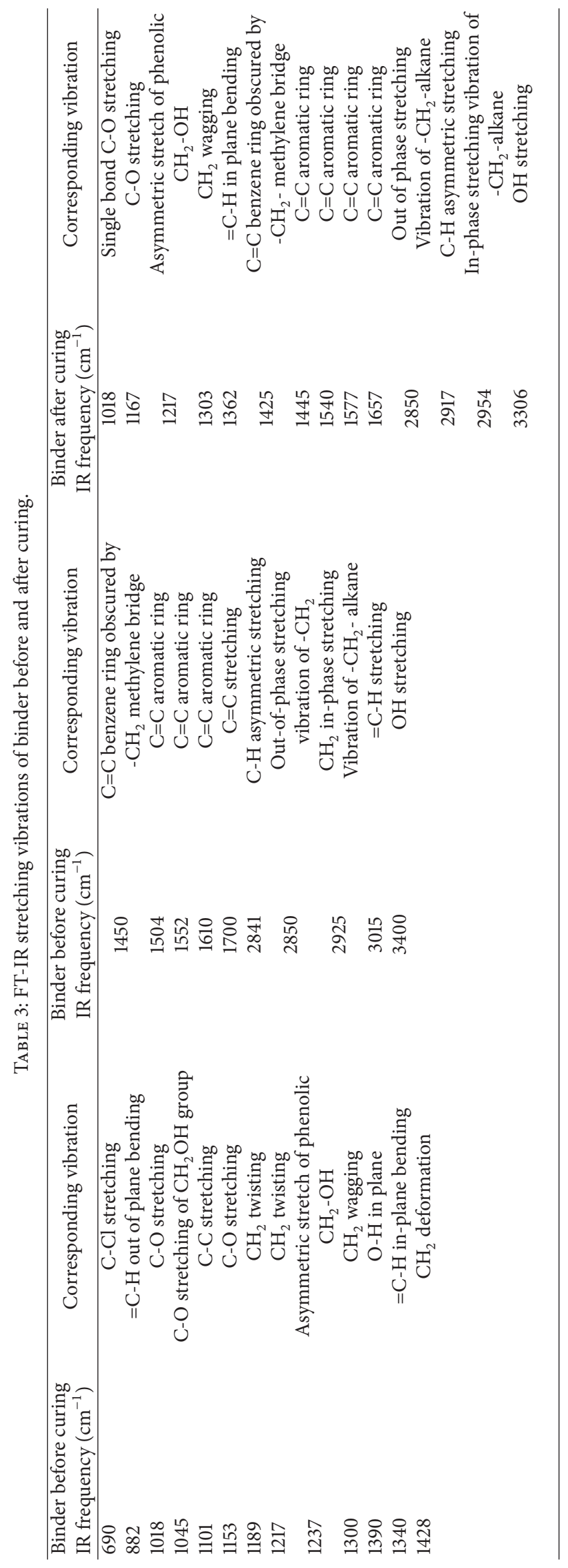




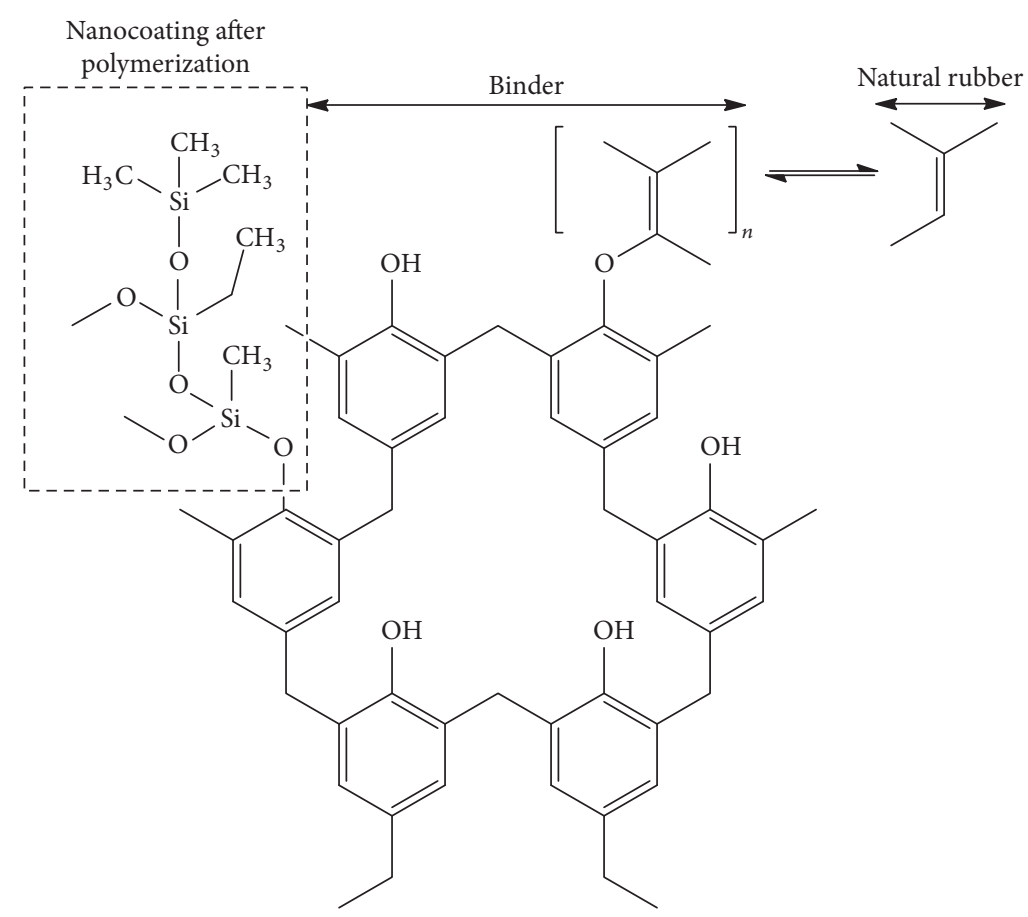

FIGURE 9: Structure of the nanocoating and binder after polycondensation.

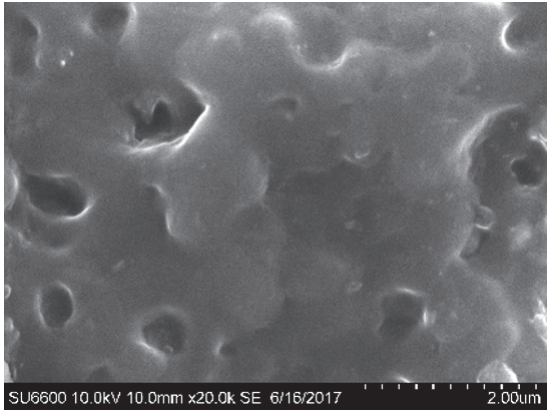

(a)

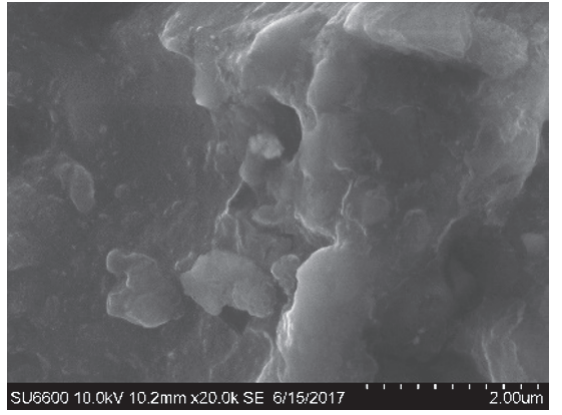

(b)

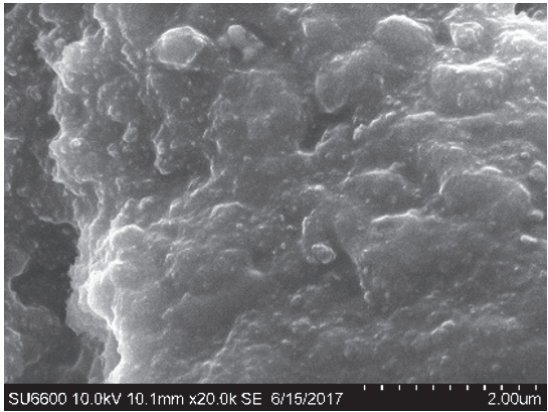

(c)

FIGURE 10: SEM images of (a) natural rubber surface, (b) dipped coated natural rubber surface, and (c) spray coated natural rubber surface.

comparison to the spray coated surfaces, the dipped coated rubber surface has a relatively smooth surface morphology with an average thickness of $600 \mathrm{~nm}$ and root mean square roughness of $70 \mathrm{~nm}$. This observation corroborates the contact angle measurements and, more importantly, the presence of thin and uniform layer on the spray coated rubber surfaces helps to retain the mechanical properties of the original rubber matrix.

3.6. Water Contact Angle (WCA), Sliding Angle (SA), and Durability of the Nanocoating. The initial water contact angle was $151^{\circ}$ and $149^{\circ}$ for spray coated and dipped coated gloves, respectively, while the uncoated gloves demonstrated a contact angle of $35^{\circ}$. Sliding angles for spray coated and dipped coated gloves were $7^{\circ}$ and $8^{\circ}$, respectively. Durability of the coating was measured by recording the resulting WCA after each abrasion cycle (Table 5) as shown in Figure 13.
A significantly durable coating was created when the spray coating method was used. Even after 40 cycles the change in WCA was insignificant.

The coated rubber films did not demonstrate oleophobic property as the oil droplets spread over the coated glove immediately after the contact. Similar observation was obtained when the coated rubber was contacted with low molecular weight organic solvents.

3.7. Permeability of Nanocoating towards Organic Solvents and Organic Acids. The permeation resistivity of the rubber films was tested against methanol and formic acid, since there is an increased demand for gloves which are dilute acid and low molecular weight solvent resistant. According to the NMR data (see supplementary data), spray coated gloves were resistant to methanol permeation for $40 \mathrm{~min}$ compared to $20 \mathrm{~min}$ for uncoated gloves. Even after $40 \mathrm{~min}$ there was no evidence 


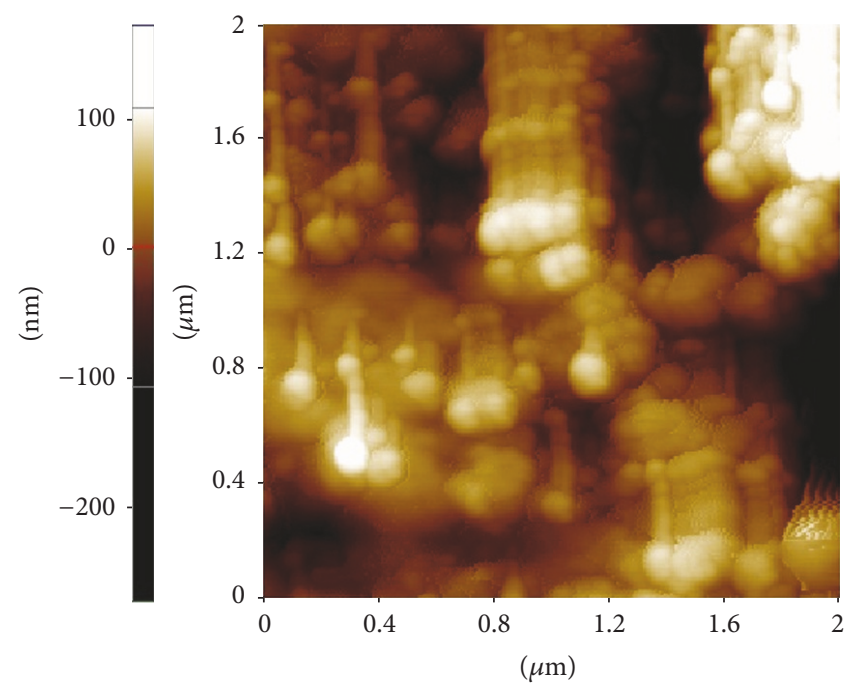

(a)

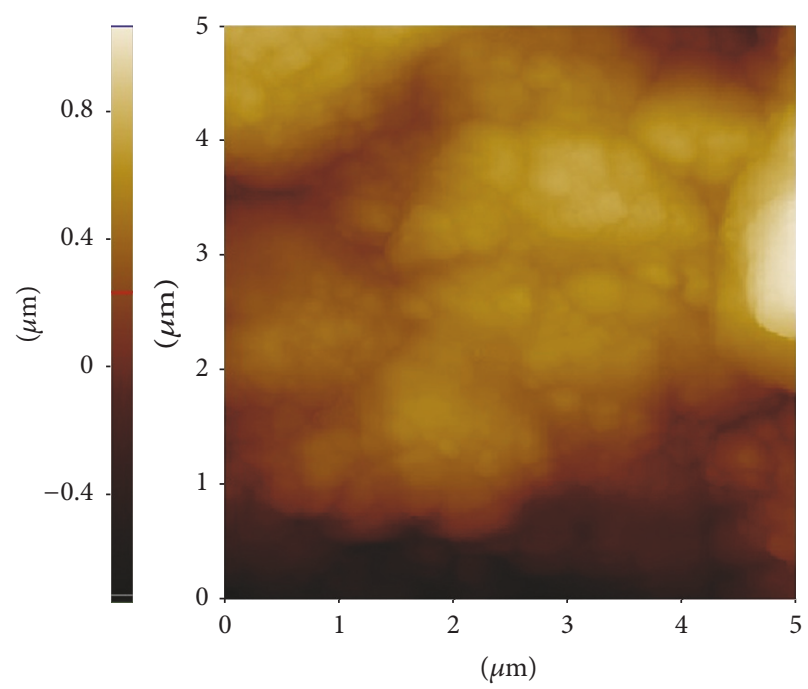

(b)

Figure 11: Topological view of (a) spray coated natural rubber surface and (b) dipped coated natural rubber surface.

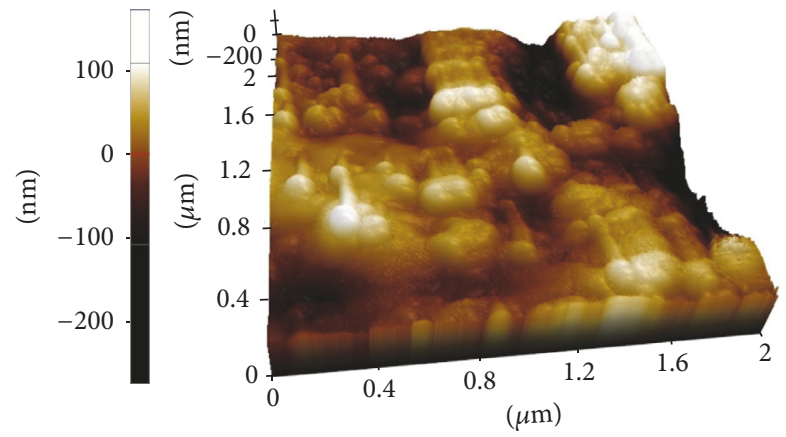

(a)

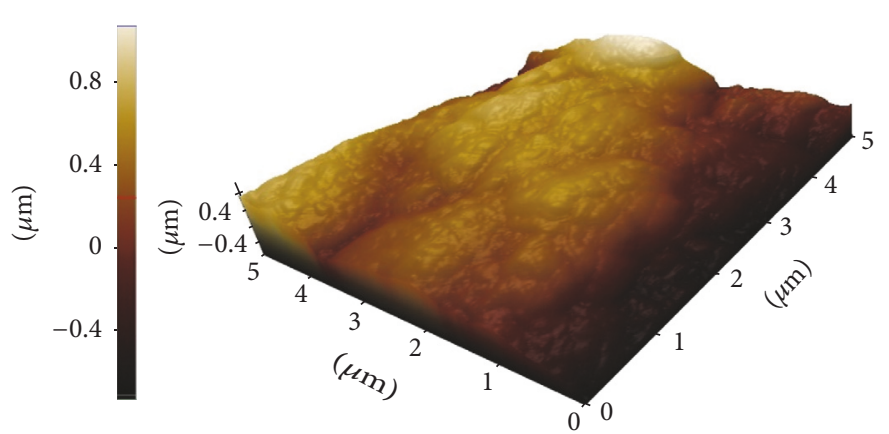

(b)

FIGURE 12: Three-dimensional topological view of (a) spray coated natural rubber surface and (b) dipped coated natural rubber surface.

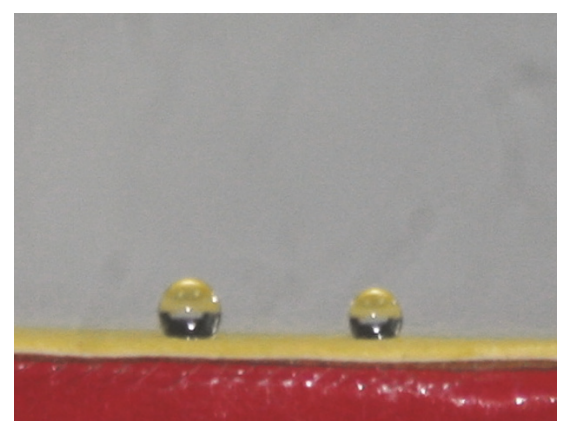

(a)

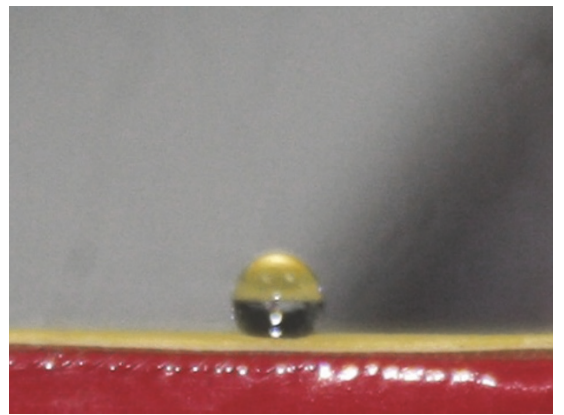

(b)

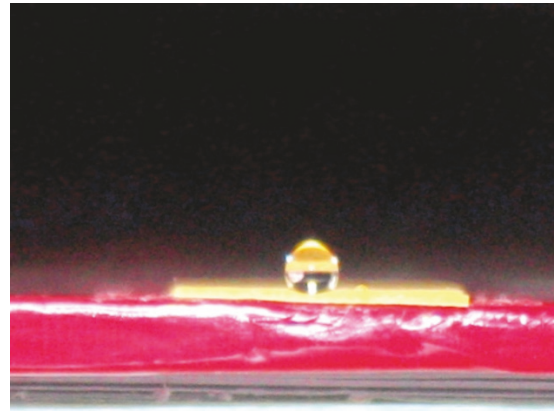

(c)

FIGURE 13: (a) WCA after 2 cycles, (b) WCA after 6 cycles, and (c) WCA after 10 cycles of spray coated rubber glove.

of methanol penetrating through coated film confirming its significant resistivity against organic solvent penetration.

As shown by SEM images in Figure 14 there are no significant changes in the surface morphology of coated glove after exposure to methanol. This further confirms the argument given above. However, there was no significant resistivity towards formic acid.

\section{Conclusions}

Superhydrophobic coatings on natural rubber surfaces were successfully fabricated using modified silica nanoparticle dispersions. The films were prepared using both dipped and spray coating methods. The water contact angle of more than $150^{\circ}$ was observed for the coatings. Sliding angles for 


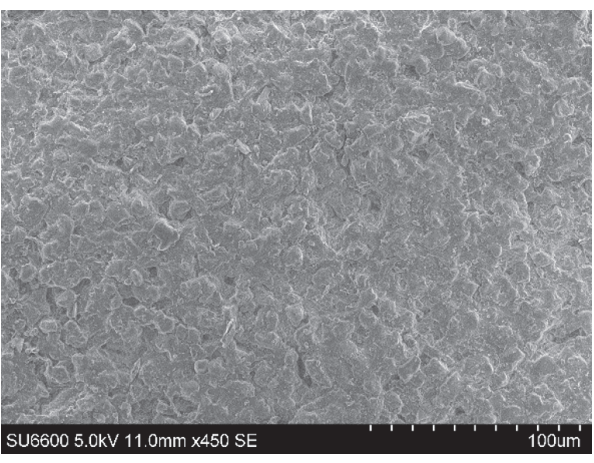

(a)

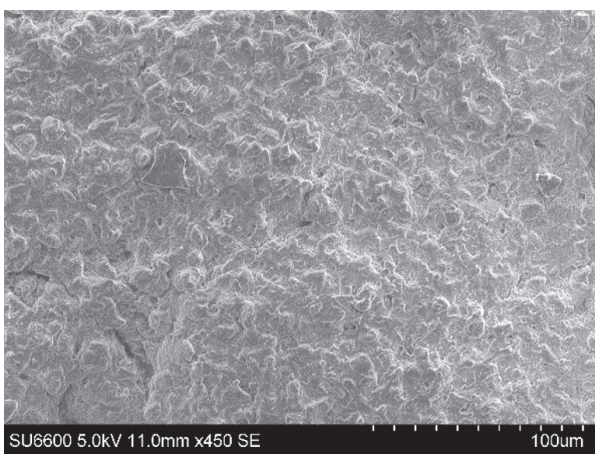

(b)

FigurE 14: SEM images of (a) coated rubber surface before methanol exposure and (b) after exposure of 40 min to methanol.

TABLE 4: Elemental percentages of the nanocoating.

\begin{tabular}{lccr}
\hline $\begin{array}{l}\text { Element } \\
\text { line }\end{array}$ & $\begin{array}{c}\text { Average } \\
\text { weight } \%\end{array}$ & $\begin{array}{c}\text { Average } \\
\text { weight\% } \\
\text { error }\end{array}$ & $\begin{array}{c}\text { Average } \\
\text { atom } \%\end{array}$ \\
\hline C K & 28.96 & \pm 1.46 & 43.03 \\
O K & 24.64 & \pm 0.35 & 27.49 \\
Al K & 0.00 & - & 0.00 \\
Si K & 46.40 & - & - \\
Si L & - & & 100.00 \\
Total & 100.00 & & 29.48 \\
\hline
\end{tabular}

TABLE 5: Resistance towards abrasion of coated natural rubber surfaces.

\begin{tabular}{lccc}
\hline Dipped coated glove & $\begin{array}{c}\text { Spray coated glove } \\
\text { Contact angle } \\
\text { (degrees) }\end{array}$ & $\begin{array}{c}\text { Number of cycles } \\
\text { Contact angle } \\
\text { (degrees) }\end{array}$ \\
\hline 0 & 149 & 2 & 151 \\
5 & 148 & 5 & 151 \\
10 & $85^{*}$ & 6 & 151 \\
- & - & 10 & 151 \\
- & - & 15 & 149 \\
- & - & 20 & 149 \\
- & - & 25 & 149 \\
- & - & 30 & 149 \\
- & - & 40 & 147 \\
\hline
\end{tabular}

${ }^{*}$ Data was not recorded after the superhydrophobic contact angle reached $85^{\circ}$ in the dipped coated gloves.

spray and dipped coated gloves were $7^{\circ}$ and $8^{\circ}$, respectively. However, according to the evidences obtained by AFM imaging, continuous and nanoporous coating with $100 \mathrm{~nm}$ thickness and root mean square roughness of $81 \mathrm{~nm}$ was observed for spray coated gloves, while the dipped coated gloves demonstrated high smoothness with a coating thickness of $600 \mathrm{~nm}$ and root mean square roughness of $70 \mathrm{~nm}$ in the surface. In addition, the mechanical properties were maintained compared to the uncoated rubber matrix when the coating was sprayed. In addition, the coating was durable even after being subjected to abrasion for a prolonged time.
This observation together with the FT-IR characterization evidences suggests that there are strong interactions between the coating and the rubber surface. Interestingly, the coatings were significantly resistant towards methanol, suggesting its potential in low molecular weight solvent resistant applications.

\section{Conflicts of Interest}

The authors declare that there are no conflicts of interest regarding the publication of this article. 


\section{Acknowledgments}

Analytical support by Dr. Gayani Abeyaweera, Dr. Nuwan De Silva, and Mr. Eranda Karunarathna is acknowledged. The authors are also grateful to Kosala Lakmal and Eshan Malintha for engineering and technical support.

\section{References}

[1] V. Karunaratne, N. Kottegoda, and A. de Alwis, "Nanotechnology in a world out of balance," Journal of the National Science Foundation of Sri Lanka, vol. 40, no. 1, pp. 3-8, 2012.

[2] M. Shateri Khalil-Abad and M. E. Yazdanshenas, "Superhydrophobic antibacterial cotton textiles," Journal of Colloid and Interface Science, vol. 351, no. 1, pp. 293-298, 2010.

[3] Q. Zhu, Q. Gao, Y. Guo, C. Q. Yang, and L. Shen, "Modified silica sol coatings for highly hydrophobic cotton and polyester fabrics using a one-step procedure," Industrial and Engineering Chemistry Research, vol. 50, no. 10, pp. 5881-5888, 2011.

[4] R. Blossey, "Self-cleaning surfaces-Virtual realities," Nature Materials, vol. 2, no. 5, pp. 301-306, 2003.

[5] M. Manca, A. Cannavale, L. De Marco, A. S. Aricò, R. Cingolani, and G. Gigli, "Durable superhydrophobic and antireflective surfaces by trimethylsilanized silica nanoparticles-based sol-gel processing," Langmuir, vol. 25, no. 11, pp. 6357-6362, 2009.

[6] Q. F. Xu, J. N. Wang, and K. D. Sanderson, "Organic-inorganic composite nanocoatings with superhydrophobicity, good transparency, and thermal stability," ACS Nano, vol. 4, no. 4, pp. 22012209, 2010.

[7] M. Ma and R. M. Hill, "Superhydrophobic surfaces," Current Opinion in Colloid \& Interface Science, vol. 11, no. 4, pp. 193-202, 2006.

[8] P. S. Brown and B. Bhushan, "Mechanically durable, superoleophobic coatings prepared by layer-by-layer technique for anti-smudge and oil-water separation," Scientific Reports, vol. 5, article 8701, 2015.

[9] L. Jiang, Y. Zhao, and J. Zhai, "A lotus-leaf-like superhydrophobic surface: a porous microsphere/nanofiber composite film prepared by electrohydrodynamics," Angewandte Chemie, vol. 43, no. 33, pp. 4338-4341, 2004.

[10] T. S. Kustandi, V. D. Samper, D. K. Yi, W. S. Ng, P. Neuzil, and W. Sun, "Self-assembled nanoparticles based fabrication of gecko foot-hair-inspired polymer nanofibers," Advanced Functional Materials, vol. 17, no. 13, pp. 2211-2218, 2007.

[11] L. Zhai, M. C. Berg, F. Ç. Cebeci et al., "Patterned superhydrophobic surfaces: toward a synthetic mimic of the namib desert beetle," Nano Letters, vol. 6, no. 6, pp. 1213-1217, 2006.

[12] X. Gao and L. Jiang, "Water-repellent legs of water striders," Nature, vol. 432, no. 7013, p. 36, 2004.

[13] F. Shi, J. Niu, J. Liu et al., "Towards understanding why a superhydrophobic coating is needed by water striders," Advanced Materials, vol. 19, no. 17, pp. 2257-2261, 2007.

[14] H. Yu, X. Liang, J. Wang, M. Wang, and S. Yang, "Preparation and characterization of hydrophobic silica aerogel sphere products by co-precursor method," Solid State Sciences, vol. 48, article 5175, pp. 155-162, 2015.

[15] S. A. Seyedmehdi, H. Zhang, and J. Zhu, "Superhydrophobic RTV silicone rubber insulator coatings," Applied Surface Science, vol. 258, no. 7, pp. 2972-2976, 2012.
[16] J. E. Mates, I. S. Bayer, J. M. Palumbo, P. J. Carroll, and C. M. Megaridis, "Extremely stretchable and conductive waterrepellent coatings for low-cost ultra-flexible electronics," Nature Communications, vol. 6, article 8874, 2015.

[17] I. S. Bayer, A. Steele, P. Martorana, E. Loth, S. J. Robinson, and D. Stevenson, "Biolubricant induced phase inversion and superhydrophobicity in rubber-toughened biopolymer/organoclay nanocomposites," Applied Physics Letters, vol. 95, no. 6, article 063702, 2009.

[18] S. A. Seyedmehdi, H. Zhang, and J. Zhu, "Influence of production method, silicone type and thickness on silicon rubber superhydrophobic coatings," Progress in Organic Coatings, vol. 90, pp. 291-295, 2016.

[19] A. Kato, Y. Kokubo, R. Tsushi, and Y. Ikeda, "Hydrophobic and hydrophilic silica-filled cross-linked natural rubber (NR): structure and properties," Chemistry, Manufacture and Applications of Natural Rubber, vol. 1, pp. 193-215, 2014.

[20] J. T. Simpson, S. R. Hunter, and T. Aytug, "Superhydrophobic materials and coatings: a review," Reports on Progress in Physics, vol. 78, no. 8, Article ID 086501, 2015.

[21] A. Milionis, J. Languasco, E. Loth, and I. S. Bayer, "Analysis of wear abrasion resistance of superhydrophobic acrylonitrile butadiene styrene rubber (ABS) nanocomposites," Chemical Engineering Journal, vol. 281, pp. 730-738, 2015.

[22] S. Liu, X. Liu, S. S. Latthe et al., "Self-cleaning transparent superhydrophobic coatings through simple sol-gel processing of fluoroalkylsilane," Applied Surface Science, vol. 351, pp. 897903, 2015.

[23] C. Wang, T. Wang, W. Liu et al., "The in vitro estrogenic activities of polyfluorinated iodine alkanes," Environmental Health Perspectives, vol. 120, no. 1, pp. 119-125, 2012.

[24] K. Steenland, T. Fletcher, and D. A. Savitz, "Epidemiologic evidence on the health effects of perfluorooctanoic acid (PFOA)," Environmental Health Perspectives, vol. 118, no. 8, pp. 1100-1108, 2010.

[25] G. Alessandrini, M. Aglietto, V. Castelvetro, F. Ciardelli, R. Peruzzi, and L. Toniolo, "Comparative evaluation of fluorinated and unfluorinated acrylic copolymers as water-repellent coating materials for stone," Journal of Applied Polymer Science, vol. 76, no. 6, pp. 962-977, 2000.

[26] H. Maleki, L. Durães, and A. Portugal, "An overview on silica aerogels synthesis and different mechanical reinforcing strategies," Journal of Non-Crystalline Solids, vol. 385, pp. 55-74, 2014.

[27] J. M. Schultz, K. I. Jensen, and F. H. Kristiansen, "Super insulating aerogel glazing," Solar Energy Materials and Solar Cells, vol. 89, no. 2-3, pp. 275-285, 2005.

[28] S. D. Bhagat, Y.-H. Kim, Y.-S. Ahn, and J.-G. Yeo, "Rapid synthesis of water-glass based aerogels by in situ surface modification of the hydrogels," Applied Surface Science, vol. 253, no. 6, pp. 3231-3236, 2007.

[29] A. Venkateswara Rao and S. D. Bhagat, "Synthesis and physical properties of TEOS-based silica aerogels prepared by two step (acid-base) sol-gel process," Solid State Sciences, vol. 6, no. 9, pp. 945-952, 2004.

[30] R. D. Herculano, A. A. A. de Queiroz, A. Kinoshita, O. N. Oliveira Jr., and C. F. O. Graeff, "On the release of metronidazole from natural rubber latex membranes," Materials Science and Engineering C, vol. 31, no. 2, pp. 272-275, 2011.

[31] S. Mohapatra and G. B. Nando, "Chemical modification of natural rubber in the latex stage by grafting cardanol, a waste 
from the cashew industry and a renewable resource," Industrial and Engineering Chemistry Research, vol. 52, no. 17, pp. 59515957, 2013.

[32] C. J. Brinker and G. W. Scherer, Sol-gel Science-The Physics and Chemistry of Sol Gel Processing, Academic, New York, NY, USA, 1990. 

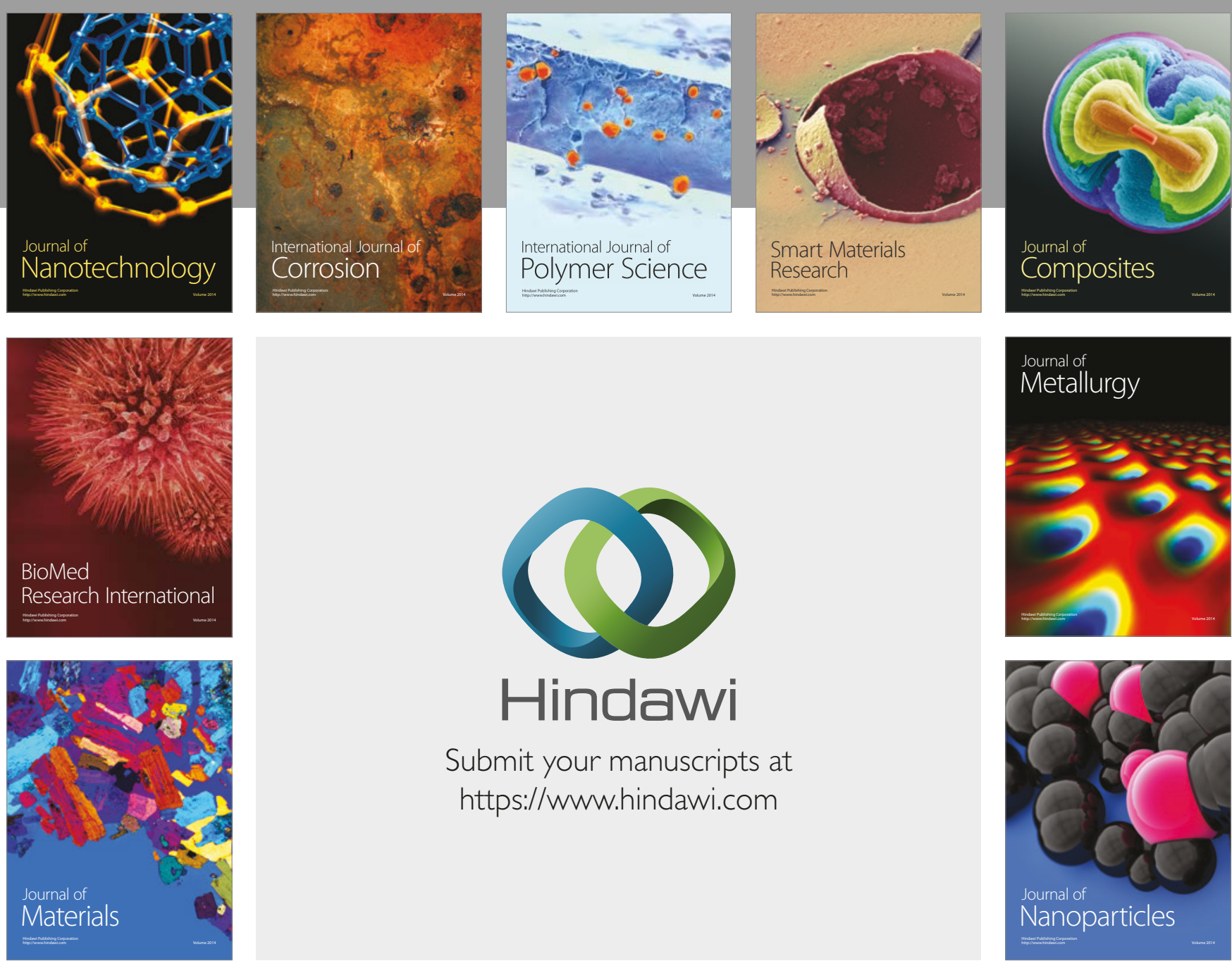

\section{Hindawi}

Submit your manuscripts at

https://www.hindawi.com
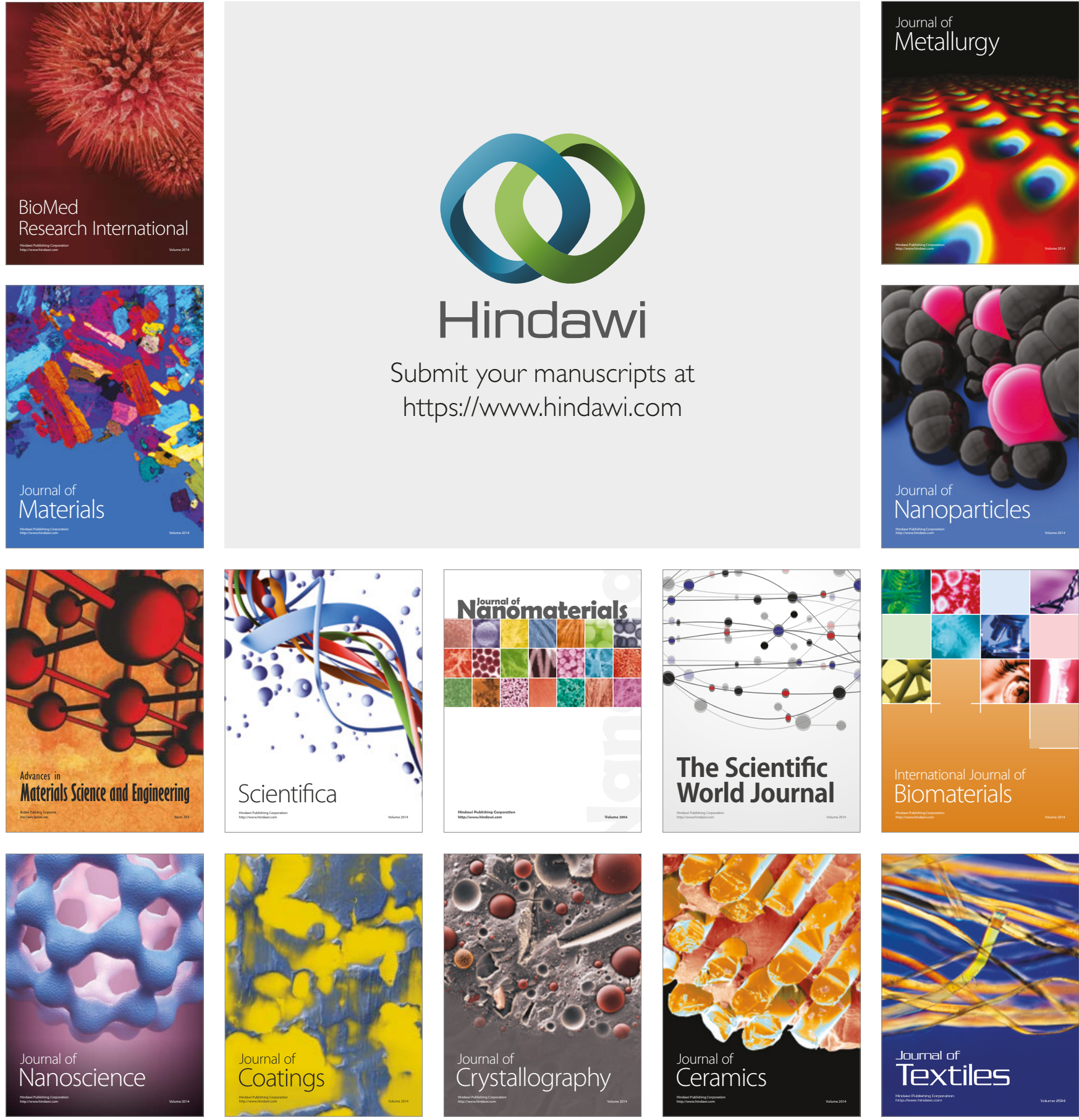

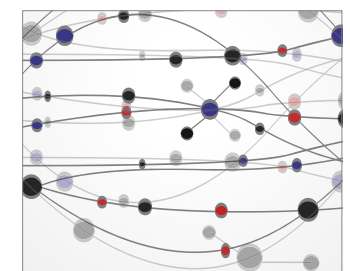

The Scientific World Journal
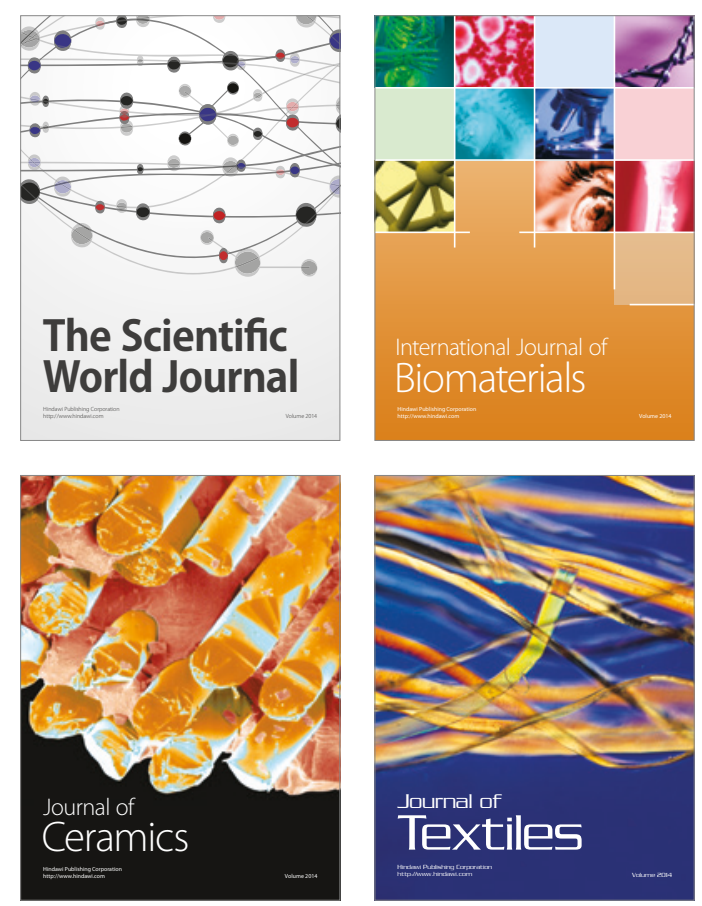